\title{
A Comparison of Vocabulary Learning Strategies of Iranian EFL University Students: Repeating versus Cooperating with Peers
}

\author{
Maki Naeimi ${ }^{1} \&$ Thomas Chow Voon Foo ${ }^{1}$ \\ ${ }^{1}$ School of Languages, Literacies and Translation Universiti Sains Malaysia, Penang, Malaysia \\ Correspondence: Maki Naeimi, Ph.D. Candidate of TESL at School of Languages, Literacies and Translation \\ Universiti Sains Malaysia, 11800, Penang, Malaysia. E-mail: makinaeimi@yahoo.com
}

Received: April 9, 2014 Accepted: May 16, 2014 Online Published: June 13, 2014

doi:10.5539/elt.v7n7p102 URL: http://dx.doi.org/10.5539/elt.v7n7p102

\begin{abstract}
Vocabulary learning and assessment are considered as the key basis for the training of English as a foreign language. However, it is time-consuming, uncertain and repetitious for the teachers to assess the proficiency of the students' vocabulary storage. This paper reports the results of a study which aimed to investigate the effect of Repeating as a direct vocabulary learning strategy versus Cooperating with Peers as an indirect vocabulary learning strategy teaching on the improvement of word knowledge on reading comprehension skill of Iranian undergraduate students. In order to attain the aim of the research, a vocabulary test was administrated to one hundred and forty-six male and female pre-intermediate EFL university students. Ultimately, seventy-eight pre-intermediate language learners were elected and appointed into two experimental groups (A and B) based on a vocabulary pre-test. The group (A) was taught vocabulary through Using Repeating vocabulary learning strategy and the group (B) was taught Cooperating with Peers vocabulary learning strategy for the aim of improving their lexical knowledge in reading comprehension skill. In the end of the treatment period, another vocabulary test (post-test) was implemented to all the students of two groups. After analyzing the data of the study that administered through using Independent samples t-test statistics, the results showed that there was a considerable difference between the two experimental groups under analysis in terms of their vocabulary improvements. The outcomes revealed that Repeating as a direct vocabulary learning strategy can cause to higher accomplishments of word storage in reading comprehension skill of Iranian pre-intermediate EFL undergraduate learners.
\end{abstract}

Keywords: cooperating with peers strategy, repeating strategy, vocabulary learning strategy

\section{Introduction}

Considering the point that English language has long been the language of correspondence in all over the world as well as most significant second or foreign language in the non-English speaking countries, so this language is supposed one of the extremity substantial languages in the world (Liu, 2009; Liu et al., 2010). In numerous territories, English language is believed the most significant foreign or second language (Laborda, Magal-Royo, Rocha, \& Álvarez, 2010; Sun et al., 2011). In this manner, this point is a necessary argument to expand a prospect proposition by which to encourage learners in acquiring English as foreign language (Liu et al., 2010).

In order to acquire another language, it is necessary to acquire a substantial amount of new vocabulary items of that language. This large exercise takes confrontations and dilemma to all foreign language learners (Krashen, 1989; Nation, 2001). Foreign language learners are commonly aware of their vocabulary knowledge constrains for making connection in the procedure of vocabulary development and enhancement (Krashen, 1989; Nation, 2001). Various researches have suggested that lexical acquisition is the basis of learning another language (Sun et al., 2011; Wilkins, 1972). As Wilkins (1972) stated, "without grammar, very little can be conveyed; without vocabulary nothing can be conveyed". Regarding this point, the opinions can be stated successfully just when learners are armed with adequate number of vocabulary with which to do so.

A study by Rubin et al. (2007) with consideration to some researches in the area of language learning strategies recommends that training learners to learn strategies, if adequately done, develops not only their ability in learning strategies but also they will be encouraged in their performance. Based on these ideas, a valuable amount of studies on the power of learning strategies training has been done to date. The common accord in the area is that acquiring strategies assures time and attempt both in and out of the classrooms atmosphere (Oxford, 
1990; Macaro, 2001; Ikeda, 2007). Specifying the high competency in teaching of learning strategies, it is reasonable that teachers try to train the strategies used by the more proficient students to less proficient ones, by that promoting or reforming their learning procedure.

Utilizing strategy for language learning is the ways enable learners to enhance their learning proficiencies. Abedini, Rahimi, and Zare-ee (2011) recognized learning strategies are methods that students apply to improve and achieve their own learning, particularly it is important for fostering learner autonomy in language learning and also as a guidance for students in developing their own success in language learning. Furthermore Language learning strategy can help English teachers achieve better comprehension of their students' prospects and contentment with their language classes (Suwanarak, 2012).

The studies which will be reviewed in the literature review section have been conducted to examine the application of vocabulary learning strategies (VLS) in general and direct and indirect vocabulary learning strategies in specific Nevertheless, since there are a small number of researches in this area in Iran, the present study is going to present a preliminary illustration of the subcategory of direct and indirect vocabulary learning strategies used by the Iranian students at pre-intermediate level. In short, this study is to measure the effectiveness of Repeating as a direct versus Cooperating with Peers as an indirect vocabulary learning strategies on the Iranian undergraduate EFL learners' vocabulary acquisition.

\section{Literature Review}

The important effect of vocabulary knowledge in comprehending language cannot be declined. In this regard, Stahl (1990) points out that vocabulary knowledge and reading comprehension are closely related to each other. Admittedly vocabulary knowledge can contribute to reading and reading can enhance vocabulary growth (Chall, 1987). Indeed, the comprehension of almost every passages whether in one's native language or in a foreign language is not feasible without understanding the text's main vocabularies (Laufer, 1997).

The significant cause to examine language learning strategies has been to assign the relation between strategy use and L2 proficiency (Anderson, 2005). As Farhady (2006) pointed out that, utilizing some types of strategies makes an approach to learning of vocabulary that impresses the level of proficiency in foreign language. More precisely, convenient strategy application results in developed prosperity in particular skills or sub-skill. Furthermore, language proficiency also impacts the use of specific vocabulary strategy use.

Vocabulary learning strategy (VLS) as subdivision of different types of language learning strategies (Cohen \& Macaro, 2007), have captivated the consideration of enormous number of researchers in all over the world (Nakamura, 2002; Catalán, 2003; Fan, 2003; Çelik \& Toptaş, 2010; Wanpen et al., 2013). This is due to the fact that having an acceptable knowledge of vocabulary storage is one of the necessity responsibilities that every learner deals with in the process of acquiring another language and, therefore, students have normally considered it the crucial task to take care of for their restricted vocabulary knowledge (Nyikos \& Fan, 2007). Such condition is principally correct for EFL situation, for example, in Iran, where exposure to the English language in everyday life is greatly restricted; consequently, learning of vocabulary is not common practice. Hence, the significance of VLSs has been given priority together with the strategies connected to the four other skills necessary in an EFL situation, namely, listening, speaking, reading, and writing (Takeuchi, 2003).

Concerning the above point, since the 1980s, many studies (McKeown et al., 1983; McKeown et al., 1985; Perfetti, \& Stafura, 2013; Poulsen, \& Elbro, 2013; Zhang et al., 2013 among others) have been conducted to find out the relationship between vocabulary knowledge and reading comprehension. Accordingly, vocabulary knowledge is a major factor which influences reading success. In fact, vocabulary knowledge can increase comprehension, but such an effect is found only when the instruction provides rich experiences with words (Stahl, 1986; Beck \& McKeown, 1991). In the same line, however, the findings of previous studies show that vocabulary study will be more productive if learners are actively involved with the words they are learning through the use of different strategies (Coomber et al., 1998).

Several scholars have lately tried to investigate possible causal relationship between lexical knowledge and the improvement of reading comprehension. Word knowledge has been considered as a linear predictor of reading comprehension (Ouellette \& Beers, 2010; Sénéchal et al., 2006; Verhoeven \& Van Leeuwe, 2008).

Marefat and Ahmadi (2003) investigated the result of training of direct vocabulary strategies of learning (memory, cognitive, and compensation) and their subcategories on long and short term retention of 60 Iranian English language learners. Actually, they didn't interest on vocabulary learning strategies; instead they examined the effect of learning strategies on vocabulary retention. The findings as presented by the students in the questionnaire; showed that cognitive and memory strategies were used more than other strategies. In addition, 
students' strategy usage in the period of short-term retention vocabulary was more efficient than in long-term retention. What is more, the findings illustrated the priority of memory strategy application in long and short term retention

Elsewhere in an experimental study; Naeimi and Yaqubi (2013) studied the effect of Structure Reviewing as a sub branch of direct vocabulary learning strategy in reading comprehension of university students. They set two groups of EFL language learners at pre-intermediate language proficiency level as experimental and control group. Though both groups were taught how to utilize vocabulary learning strategies for a period of 10 weeks, only the experimental group received Structure Reviewing vocabulary learning strategy. The model of training was based on the theoretical framework for direct and indirect language learning strategies instruction suggested by Oxford (1990). The result of the study indicated that Structure Reviewing as direct strategy training could significantly enhance the vocabulary learning of Iranian pre-intermediate EFL undergraduate students.

\section{Oxford's Vocabulary Learning Strategies}

Among various researchers dealt with language learning strategies, Oxford's (1990) classification seems to be the most comprehensive particularized organization representing direct and indirect learning strategies. Oxford's (1990) classification represented direct and indirect strategies with 6 categories, 19 strategies and 62 sub-strategies. The Direct method of language learning suggested that word can be acquired by using instruments that attract the students' attention into direct communication with the form and meaning of lexical items, like word lists, dictionaries and so on. Indirect strategies support and control acquisition of language without directly involving the target language, hence they construct the profession of language learning. With the development of the theory of language learning strategies scholars have made effort to connect these strategies to other attitudes of language including vocabulary as well. Studies such as O'Malley and Chamot (1990) proved that most language learning strategies are used for vocabulary acquisition function too.

\section{Objectives of the Present Study}

In spite of allocating several years in learning English as a foreign language in different schools levels and before starting their study at university, many Iranian students do not have affluent vocabulary knowledge. Encouraging students to become engaged in VLSs is regarded to be one of the very important tools for their vocabulary enhancement. By examining the studies conducted in the area of teaching language as a foreign language, whereas, one can note that little attention has been paid to the effect of direct and indirect VLSs on Iranian EFL learners. By this study the researchers are trying to find out whether Repeating or Cooperating with peers vocabulary learning strategy affects the identification or construction of vocabulary items. Concerning the above cited objectives, the research questions were formulated as follows:

\section{Research Questions}

1) Does Using Repeating as a direct vocabulary learning strategy affect Iranian EFL learners' vocabulary learning?

2) Does cooperating with peers as an indirect vocabulary learning strategy affect Iranian EFL learners'vocabulary learning?

\section{Significance of the Study}

This research would help teachers to encourage students gain awareness of different subcategories of the Direct and Indirect language learning strategies which they utilize to enhance their vocabulary learning effectively. By focusing on the Repeating as a Direct and the Cooperating with Peers as an Indirect vocabulary learning strategies instruction and their impact on lexical knowledge improvement of the Iranian EFL university students, the present study may prove to be a help for language instructors to either implement Direct or Indirect vocabulary learning strategies for the better improvement of the language learners' vocabulary acquisition. Moreover it might assist students become knowledgeable of the ways for more effective learning. Furthermore it may also guide learners to improve vocabulary learning strategies, and ways to become more motivated and autonomous learners. Having enough knowledge of learners' vocabulary learning strategy use will enable instructors and researchers provide convenient materials and activities for enabling learners develop their vocabulary competence.

\section{Methodology}

\subsection{Participants}

The study was conducted with a number of learners who were in the second and third semester of their study programs. They were selected from different faculties at Islamic Azad University of Ahvaz, Iran. The students were required to take a General English course as a compulsory subject in the syllabus of their study. The 
participants were 78 ( 22 males and 56 females) that were selected out of 146 volunteer participants. Their ages ranged from 20 to 25, and all were non English major students drawn randomly from a bachelor program. These students were native-born Iranian whose first language was Persian and were learning English as a foreign language. They completed their secondary education in Iran secondary school and are considered pre-intermediate level in English proficiency level. They had learned English as a foreign language for about 6 years and passing English is regarded a prerequisite for entering to university.

\subsection{Instruments}

Three instruments were used for collecting data in this research study.

In this paper, the first instrument used as vocabulary test and as a pre-test, adapted from the Vocabulary Knowledge Scale (VKS) developed by Paribakht and Wesche (1993). Such test was utilized to determine the students' lexical knowledge and included of 40 multiple-choice vocabulary items. Its reliability was determined through KR-21 formula in the pilot study (0.86). The validity was also proved by three competent experts in the field who had considerable experience in test planning. Finally, 78 male and female pre-intermediate Iranian university students from Islamic Azad University, Ahvaz, Iran, were selected as participants of this study. The reason for using such vocabulary test is that, vocabulary ability is a significant element in approximately all the features of L2 competency (Zareva et al., 2005).

The second instrument consisted of 10 units reading comprehension text practices and exercises as the treatment elements which the researchers provided for groups (A and B) of the Repeating strategy and Cooperating with Peers strategy. The reading practices and exercises were identical for groups (A and B) and were selected from the book of Select Readings (Pre-intermediate level) by Lee and Gunderson (2002).

The third instrument, the post-test, constructed by the researchers included 40 multiple-choice vocabulary items selected from the 10 units that were taught during the 10 sessions of treatment period. It was given at the end of both strategies' instruction for both groups. The vocabularies assessed in posttest were all chose from new vocabularies instructed and represented in the period of the teaching procedure. The reliability $(0.83)$ and validity $(0.75)$ of the tests were calculated and verified through KR-21 formula.

\subsection{Procedure}

The current research was intended to examine the effect of two types of vocabulary learning strategies (VLSs) namely; Repeating and Cooperating with Peers, by Iranian EFL learners at undergraduate level for finer comprehension of the methods that they used to acquire new vocabulary in English. The study was administrated in Ahvaz Islamic Azad University, Khuzestan, Iran. The university is located in Southwest of Iran. It is ranked among the big Islamic Azad Universities in Iran. The concentration in this study was focused on students of nonEnglish majors. At first Vocabulary Knowledge Scale (VKS) developed by Paribakht and Wesche (1993) test was administered to 146 university students majoring in different disciplines other than English. Then, 78 learners whose marks were between one standard deviation above and one standard deviation below the mean were chosen. The test was to guarantee that there was no important difference between the language proficiency levels of the learners who participated in the test. The remaining 78 students were divided into two equal experimental groups.

During the treatment; that instructed by one of the authors (corresponding author), both groups A and B were taught the same subjects from the same book. The treatment period lasted for twelve sessions of two- hour sessions per week. The subject of first session was devoted to strategy instruction and acquainting the students becoming familiar with the strategies they are going to utilize according to the strategy type. That is, the teacher told the students what Repeating and Cooperating with peers strategies are in each group. In group (A), students were taught to acquire vocabulary through the Repeating as a Direct vocabulary learning strategy and in the other group (B) they were exposed to learn vocabulary through the Cooperating with Peers as indirect vocabulary learning strategy training.

Whole class time was devoted to train vocabulary by using the targeted strategies and more tasks and assignments on using the strategy as practice and activities. That is, to state that the students are clearly engaged in the procedure of how to utilize every taught strategy by having the information of recognizing that type of strategy. At the end of eleven session's instruction period and studying ten lessons of the book, the instructor provided the test of vocabulary that included 40 multiple-choice questions and was implemented as a post-test in the final session $\left(12^{\text {th }}\right)$. The next sections introduce the treatment period of the two strategies briefly.

\subsubsection{Repeating as Direct Vocabulary Learning Strategy}

The Repeating strategy was used to read a paragraph more than one time for better comprehension. This 
beneficial strategy is in a way to ask students read a paragraph several times, each time for different intentions: for instance, for totally grasping of the passage or to understand the main ideas of that paragraph, to anticipate, to read the paragraph for more details, to write down questions and so on. The students also take notes about the paragraph during reading and then review it one or two times (Oxford, 1990).

\subsubsection{Cooperating with Peers as Indirect Vocabulary Learning Strategy}

This type of vocabulary learning strategy consists of a concentrated effort that requires every learner to carry a task together with other students on an enterprise with a common aim. Reading comprehension activity and other effective exercises requires learners to enhance their proficiency to cooperate with peers in the procedure of engaging in vocabulary learning strategy. Reading activity, as an independent enterprise, was a cooperative exercise as well. For instance, every learner is required to cooperate with his/her group on the reading comprehension activity. Every member in a group has to take responsibility for reading one part of the text, so together with other group members constituted the whole story during the process of discussing, negotiating, requesting, and cooperating (Oxford, 1990).

\section{Results and Discussion}

In order to answer the research questions, the teacher (corresponding author) prepared the learners of two groups (A and B) to participate in a posttest session at the end of the treatment in which group A received the Repeating and group B taught the Cooperating with Peers vocabulary learning strategy. The Results of the vocabulary strategy test for both groups were compared by utilizing independent samples t-test statistical process. The findings demonstrated that the mean scores of the Repeating strategy group (group A) (Mean=37.59) was significantly $(\mathrm{t}(3.754), \mathrm{p}<.05)$ different from the Cooperating with Peers strategy group (group B) (Mean=34.31, $\mathrm{t}=0.54$ ). Tables 1 and 2 show the statistical analysis of groups A and B as Repeating strategy (Direct strategies) and Cooperating with peers (Indirect strategies) participants' pre-post tests scores.

Table 1. Descriptive statistics related to group A (repeating strategy) pre-post tests results

\begin{tabular}{lllll}
\hline Group & $\mathrm{N}$ & Mean & $\mathrm{SD}$ & t-test \\
\hline Group A pretest & 39 & 30.80 & 0.64 & 3.754 \\
Group A posttest & 39 & 37.59 & 0.78 & $\mathrm{P}=0.03$ \\
\hline
\end{tabular}

T-observed $=3.754$. T-critical $=1.729$. T-observed is bigger than $\mathrm{t}$-critical

Table 2. Descriptive statistics related to group B (cooperating with peers strategy) pre-post tests results

\begin{tabular}{lllll}
\hline Groups & $\mathrm{N}$ & Mean & $\mathrm{SD}$ & $\mathrm{t}$-test \\
\hline Group B pretest & 39 & 32.80 & 0.62 & 0.054 \\
Group B posttest & 39 & 34.31 & 0.58 & $\mathrm{P}=0.872$
\end{tabular}

T-observed $=0.054$. T-critical $=1.729$. T-observed is smaller than $\mathrm{t}$-critical

The aim of study was to investigate 78 pre-intermediate university learners from non-English majors of Ahvaz Islamic Azad University, Khuzestan, Iran in learning English as a general course. The particular purpose in this research was to explore the effect of the Repeating as a Direct and the Cooperating with Peers as an Indirect vocabulary learning strategy of the_aforementioned students.

Considering the accomplishment of group A in the pre-post tests, it should be stated that the mean score of the learners in group A in the pre-test was 30.80 out of 40 . This mean score increased to 37 in the post-test which is exhibitive of the reality that a notable improvement was made in their accomplishment. This implies that performing the Repeating as Direct vocabulary learning strategy could improve vocabulary learning of the students in group A. The results of the sample t-test for the findings gained from the pre-post tests of group A also pointed out that the enhancement was statistically significant $(\mathrm{p}<0.05)$. This means that, the Repeating strategy group outperformed the Cooperating with Peers strategy group in the vocabulary test. Thus, the Direct Repeating strategy teaching seemed to have promoted the learners' vocabulary intake.

As for the results provided by the analysis of pre-post tests for the Cooperating strategy group, the mean score in the pre-test was 32.80 out of 40 and in the post-test improved to 34.31 out of 40 . This minor development can be 
interpreted as enhancement. Nevertheless, an investigation of the two means propose that the mean for the posttest was slightly higher than the mean of the pretest. This suggests that using the Cooperating with Peers as Indirect vocabulary learning strategy compared to the Repeating as Direct strategy could not improve lexical learning of the learners in group B. The findings of the sample t-test for the data provided from group B also showed that the development was not statistically significant $(\mathrm{p}>0.05)$.

\section{Conclusions and Implications}

Vocabulary learning strategies simplify vocabulary learning. Training in the application of suitable vocabulary learning strategies is required for the language learning process to be efficient. Within teaching, vocabulary learning strategies will enable learners to learn the target language vocabulary more effectively, and to be able, eventually, to manage their own learning. The purpose of education is to retain what is learnt. Finding ways that can help learners maintain what they have already learnt is of crucial importance in any educational setting. The findings can also motivate the trainers of General English course to organize an English language learning context outside the class for learners to take part in activity at their own pace, level, and interest.

The current study designed to find answers for two questions. The first question was whether engaging Iranian' EFL learners in utilizing the Repeating as a Direct vocabulary learning strategy improves their vocabulary learning storage or not. Noting the data obtained the answer to this question was positive; that is, learners who received the Repeating vocabulary learning strategy treatment showed higher lexical learning rate. The results moreover suggested that for the second research question concerning the impact of the Cooperating with Peers vocabulary strategy, however, did not enhance considerably after their use of this Indirect vocabulary learning strategy. Although some strategies are greatly powerful learning instruments, many students are either ignorant of their existence or they use them ineffectively. As pointed out by Oxford (2003), learners are not always knowledgeable of the power of consciously using learning strategies to make learning quicker and more effective. The following outcomes can be inferred from the study:

The significant point studied in this research was the rate of improvement in the Repeating strategy application in Group A and the Cooperating with Peers strategy use in group B. The results Indicated that Group A outscored its parallel group B .This meant that teaching through the Repeating as a Direct vocabulary learning strategy was an efficient and better way of learning and retaining the vocabulary items. Regarding the focus point of this research, it is recommended that the English instructors should make the learners be aware of the significance of the Direct vocabulary leering strategy like the Repeating strategy in improving their vocabulary storage. By the Repeating strategy learning, the teachers can encourage the students to use it efficiently. It may help learners, teachers, and administrators to become aware of appropriate subcategories of VLS components, vocabulary knowledge, and competency in order to provide and deliver vocabulary education and training. According to the findings of this study, some implications can be driven. The first benefit of this research is that it may raise the knowledge on the significance of word learning strategies in English language learning and teaching.

As Oxford (2003) mentioned "Vocabulary is not explicitly taught in most language classes" (p. 9). The findings of this research can help and encourage English instructors to improve their teaching procedures. Second, trainers who are concerned with their students' performance in learning English vocabulary, can present and introduce various types of vocabulary learning strategies and techniques to their students by designing valuable activities and providing appropriate assignments. The interpretations of prior researchers lend support to the relative advantage of category and subcategory of the Direct vocabulary learning strategies teaching in enhancing students' word learning. The findings of the present research also shed more light to previous studies (Beck et al., 2002; Beck et al., 2005; Beck et al., 2007; Naeimi \& Yaqubi, 2013) which highlighted the pedagogical value of implementing category and sub-category of direct vocabulary learning strategies in language learning classrooms.

\section{Limitations of the Study}

Though the results of this research might be considered a positive contribution to a better comprehending of VLSs teaching, some limitations should be taken into consideration. First, this research covered only twelve teaching sessions, hence a more extensive research could yield more comprehensive conclusions. Second, the ability levels of the students under investigation were rather homogeneous (Pre-intermediate). Additionally, the number of participants in each group was relatively small, which restricted the generalization of the conclusion. Third, some variables which might have contributed to the results of the current research, such as choice of title and time interval between tests were not taken into consideration for both groups. It is recommended that these elements be regarded in future replications of the current research. Future research projects should preferably be directed at developing the quality of teaching with various methodologies, disciplines, and levels. 


\section{Acknowledgements}

The authors would like to acknowledge School of Languages, Literacies and Translation Universiti Sains Malaysia , 11800, Penang, Malaysia for funding the research project.

\section{References}

Abedini, A., Rahimi, A., \& Zare-ee, A. (2011). Relationship between Iranian EFL Learners' Beliefs about Language Learning, their Language Learning Strategy Use and their Language Proficiency. Procedia-Social and Behavioral Sciences, 28, 1029-1033. http://dx.doi.org/10.1016/j.sbspro.2011.11.188

Anderson, N. J. (2005). L2 strategy research. Handbook of research in second language teaching and learning, 757-772.

Beck, I., \& McKeown, M. (1991). Conditions of vocabulary acquisition. In R. Barr, M. L. Kamil, P. Mosenthal, \& P. D. Pearson (Eds.), Handbook of reading Research (Vol. 2, pp. 789-814). New York: Longman.

Beck, I. L., McKeown, M. G., \& Kucan, L. (2002). Bringing words to life: Robust vocabulary instruction. New York: Guilford.

Beck, I. L., McKeown, M. G., \& Kucan, L. (2005). Choosing words to teach. In E. H. Hiebert, \& M. L. Kamil (Eds.), Teaching and learning: Bringing research to practice (pp. 207-242). Mahwah, NJ: Lawrence Erlbaum.

Beck, I. L., \& McKeown, M. G. (2007). Different ways for different goals, but keep your eye on the higher verbal goals. In R. K. Wagner, A. E. Muse, \& K. R. Tannenbaum (Eds.), Vocabulary acquisition: Implications for reading comprehension (pp. 182-204). New York: Guilford.

Catalan, R. M. J. (2003). Sex differences in L2 vocabulary learning strategies. International Journal of Applied Linguistics, 13(1), 54-77.

Çelik, S., \& Toptaş, V. (2010). Vocabulary learning strategy use of Turkish EFL learners. Procedia-Social and Behavioral Sciences, 3, 62-71.

Chall, J. S. (1987). Two vocabularies for reading: Recognition and meaning. In M. McKeown, \& M. Curtis (Eds.), The Nature of Vocabulary Acquisition (pp. 7-17). Lawrence Erlbaum Association, New Jersey.

Cohen, A. D., \& Macaro, E. (2007). Language learning strategies: Thirty years of research and practice. Oxford: Oxford University Press.

Coomber, J. E., Peet, H. D., \& Smith, C. B. (1998). Teaching Vocabulary. Fargo, ND: Division of Continuing Education, North Dakota State University.

Fan, M. Y. (2003). Frequency of use, perceived usefulness, and actual usefulness of second language vocabulary strategies: A study of Hong Kong learners. The Modern Language Journal, 87(2), 222-241.

Farhadi, H. (2006). Twenty-five years of living with applied linguistics: Collection of articles. Iran, Tehran. Rahnama press.

Ikeda, M. (2007). EFL reading strategies: Empirical studies and an instructional model. Tokyo: Shohakusha.

Krashen, S. (1989). We acquire vocabulary and spelling by reading: Additional evidence for the input hypothesis. The modern language journal, 73(4), 440-464.

Laborda, J. G., Magal-Royo, T., de Siqueira Rocha, J. M., \& Álvarez, M. F. (2010). Ergonomics factors in English as a foreign language testing: The case of PLEVALEX. Computers \& Education, 54(2), 384-391.

Laufer, B., \& Shmueli, K. (1997). Memorizing new words: Does teaching haveanything to do with it? RELC Journal, 28(1), 89-106. Retrieved from http://rel.sagepub.com/content/28/1/89.full.pdf

Lee, L., \& Gunderson, E. (2002). Select readings: Pre-intermediate level. Oxford University Press.

Liu, P. L., Chen, C. J., \& Chang, Y. J. (2010). Effects of a computer-assisted concept mapping learning strategy on EFL college students' English reading comprehension. Computers \& Education, 54(2), 436-445.

Liu, T. Y. (2009). A context-aware ubiquitous learning environment for language listening and speaking. Journal of Computer Assisted Learning, 25(6), 515-527. http://dx.doi.org/10.1111/j.1365-2729.2009.00329.x

Macaro, E. (2001). Learning strategies in foreign and second language classrooms. London: Continuum.

Marefat, H., \& Ahmadi, M. S. (2003). The Impact of Teaching Direct Learning Strategies on the Retention of Vocabulary by ELF Learners. The Reading Matrix, 3(1), 86-99. 
McKeown, M. G., Beck, I. T., Omanson, R. C., \& Perfetti, C. A. (1983). The effects of long-term vocabulary instruction on reading comprehension: A replication. Journal of Reading Behavior, 15, 3-18. Retrieved from http://jlr.sagepub.com/content/15/1/3.full.pdf

McKeown, M. G., Beck, I. L., Omanson, R. C., \& Pople, M. T. (1985). Some effects of the nature and frequency of vocabulary instruction on the knowledge and use of words. Reading Research Quarterly, 20, 522-535.

Naeimi, M., \& Yaqubi. (2013). The Study of Direct Vocabulary Learning Strategy on EFL Iranian' Reading Comprehension: The Case of Structure Reviewing. Elixir International Journal, 57(2013), 14067-14070. Retrieved form http://www.elixirpublishers.com/articles/1364982951_57\%20(2013)\%2014067-14070.pdf

Nakamura, T. (2002). Vocabulary learning strategies: The case of Japanese learners of English. Kyoto: Koyo Shobo.

Nation, I. S. (2001). Learning vocabulary in another language. Cambridge: Cambridge University Press.

Nyikos, M., \& Fan, M. (2007). A review of vocabulary learning strategies: Focus on language proficiency and learner voice. In A. Cohen, \& E. Macaro (Eds.), Language learning strategies: Thirty years of research and practice (pp. 251-274). Oxford: Oxford University Press.

O’Malley, J. M., \& Chamot, A. U. (1990). Learning strategies in second language acquisition. Cambridge: Cambridge University Press.

Ouellettte, G., \& Beers, A. (2010). A not-so-simple view of reading: How oral vocabulary and visual-word recognition complicate the story. Reading and Writing, 23, 189-208.

Oxford, R. (1990). Language learning strategies: What every teacher should know. New York: Newbury House.

Oxford, R. (2003). Toward a More Systematic Model Pf L2 Learner Autonomy. In P. Palfreyman, \& R. Smith (Eds.), Learner Autonomy across Cultures: Language Education Perspectives (pp. 75-91). Great Britain: Palgrave Macmillan.

Perfetti, C., \& Stafura, J. (2013). Word knowledge in a theory of reading comprehension. Scientific Studies of Reading, (ahead-of-print), 1-16. http://dx.doi.org/10.1080/10888438.2013.827687

Poulsen, M., \& Elbro, C. (2013). What's in a Name Depends on the Type of Name: The Relationships between Semantic and Phonological Access, Reading Fluency, and Reading Comprehension. Scientific Studies of Reading, 17(4), 303-314. http://dx.doi.org/10.1080/10888438.2012.692743

Rubin, J., Chamot, A., Harris, V., \& Anderson, N. (2007). Intervening the use of strategies. In A. D. Cohen, \& E. Macaro (Eds.), Language learning strategies: Thirty years of research and practice (pp. 141-160). Oxford: Oxford University Press.

Sénéchal, M., Ouellette, G., \& Rodney, D. (2006). The misunderstood giant: On the predictive role of early vocabulary in future reading. In D. Dickinson, \& S. B. Neuman (Eds.), Handbook of Early Literacy Research (Vol. 2, pp. 173-184). New York, NY: Guilford Press.

Sun, K. T., Huang, Y. M., \& Liu, M. C. (2011). A WordNet-Based Near-Synonyms and Similar-Looking Word Learning System. Educational Technology \& Society, 14(1), 121-134.

Stahl, S. A. (1986). Three Principles of Effective Vocabulary Instruction. Journal of Reading, 29(7), 662-668.

Stahl, S. A. (1990). Beyond the Instrumental Hypothesis: Some Relationships between Word Meanings and Comprehension. Technical report no. 505 of the Center for the Study of Reading. University of Illinois at Urbana- Champaign.

Suwanarak, K. (2012). English language learning beliefs, learning strategies and achievement of Masters students in Thailand. TESOL IN CONTEXT.

Takeuchi, O. (2003). What can we learn from good foreign language learners? A qualitative study in the Japanese foreign language context. System, 31(3), 385-392. http://dx.doi.org/10.1016/S0346-251X(03)00049-6

Verhoeven, L., \& van Leeuwe, J. (2008). Prediction of the development of reading comprehension: A longitudinal study. Applied Cognitive Psychology, 22, 407-423.

Wanpen, S., Sonkoontod, K., \& Nonkukhetkhong, K. (2013). Technical Vocabulary Proficiencies and Vocabulary Learning Strategies of Engineering Students. Procedia-Social and Behavioral Sciences, 88, 312-320.

Wilkins, D. A. (1972). Linguistics in language teaching. London: Edward Arnold.

Zareva, A., Schwanenflugel, P., \& Nikolova, Y. (2005). Relationship between lexical competence and language 
proficiency: Variable sensitivity. Studies in Second Language Acquisition, 27(04), 567-595.

Zhang, Y., Tardif, T., Shu, H., Li, H., Liu, H., McBride-Chang, C., ... Zhang, Z. (2013). Phonological skills and vocabulary knowledge mediate socioeconomic status effects in predicting reading outcomes for Chinese children. Developmental psychology, 49(4), 665.

\section{Authors Information}

Maki Naeimi is Ph.D. candidate in TESL at the school of Languages, Literacies and Translation at Universiti Sains Malaysia (USM). He has taught English and ESP courses for undergraduate students at Islamic Azad University in Iran since 2009. His research interests are ESP, language learning strategies, teaching methodology and discourse analysis.

Thomas Chow Voon Foo has a Ph.D. in English Studies from Universiti Sains Malaysia (USM), Penang. He is currently a senior lecturer at USM and teaches B.A. courses in Sociolinguistics, English Literature and Second Language Learning at the School of Languages, Literacies and Translation. His research interests are in methodologies and practices in the teaching of English, especially in the areas of writing and literacy education.

\section{Copyrights}

Copyright for this article is retained by the author(s), with first publication rights granted to the journal.

This is an open-access article distributed under the terms and conditions of the Creative Commons Attribution license (http://creativecommons.org/licenses/by/3.0/). 